Introduction: Sunitinib is a standard of care first line treatment for patients with metastatic renal cell carcinoma (RCC). Sunitinib standard dose is $50 \mathrm{mg}$ once daily for 4 consecutive weeks followed by 2 weeks' off (4/2 schedule). Long-term and high exposure to this medication lead to severe adverse events (AEs); therefore, this trial was done to find the best schedule which gives the best outcome with minimal toxicity.

Materials and methods: Seventy patients were randomly assigned into 2 groups, then received $50 \mathrm{mg} /$ day of sunitinib. Group 1 (40 patients) received sunitinib for 4 consecutive weeks followed by 2 weeks off (4/2 schedule) while 30 patients were admitted to group 2 with 2 weeks on and 1 week off (2/1 schedule).

Results: All patients (100\%) had significantly higher AEs on schedule 4/2 vs. $73.3 \%$ on schedule $2 / 1(p=0.001)$. Furthermore, the grade 3 AEs on schedule $2 / 1$ were significantly lower than those on schedule $4 / 2(26.7 \%$ vs. $82.5 \%)$ respectively $(p=0.001)$, such as fatigue, diarrhea, hypertension, hand foot syndrome (HFS) and mucositis. Progression-free survival (PFS) rate was significantly higher in $2 / 1$ schedule $(60.9 \%$ vs. $38.6 \%)$ than in $4 / 2$ schedule $(p<0.008)$. Multivariate analysis suggested that: age $>60$ years, poor International Metastatic RCC Database Consortium (IMDC) risk category, tumor size $>10 \mathrm{~cm}$ and treatment schedule (group 1) were poor prognostic factors of PFS.

Conclusions: Our study supported the use of $2 / 1$ schedule of sunitinib in patients with metastatic RCC because of lower toxicity profile and better efficacy with improved PFS in comparison to $4 / 2$ schedule.

Key words: metastatic renal cell carcinoma, sunitinib, 4/2 schedule, 2/1 schedule, adverse events, outcome.

Contemp Oncol (Pozn) 2020; 24 (4): 221-228 DOI: https://doi.org/10.5114/wo.2020.102802

\section{Tolerability and outcome of sunitinib by giving $4 / 2$ schedule versus $2 / 1$ schedule in metastatic renal cell carcinoma patients: a prospective randomized multi-centric Egyptian study}

Lobna A. Abdelaziz' ${ }^{1}$, Heba F. Taha², Magid M. Ali³ , Marwa I. Abdelgawad ${ }^{4}$, Amira Elwan ${ }^{1}$

${ }^{1}$ Clinical Oncology and Nuclear Medicine Department, Faculty of Medicine, Zagazig University, Zagazig, Egypt

${ }^{2}$ Medical Oncology Department, Faculty of Medicine, Zagazig University, Zagazig, Egypt ${ }^{3}$ Urology Department, Faculty of Medicine, Zagazig University, Zagazig, Egypt ${ }^{4}$ Clinical Oncology Department, Faculty of Medicine, Assiut University, Assiut, Egypt

\section{Introduction}

Metastatic renal cell carcinoma (RCC) is represented by $20-30 \%$ of all kidney cancers. After radical surgery, nearly one third of the localized RCC are expected to develop distant metastases [1].

Sunitinib malate is an oral multi-target tyrosine kinase inhibitor for both vascular endothelial growth factor (VEGF) and platelet-derived growth factor (PDGF) receptors [2-4]. It was approved by the Food and Drug Administration (FDA) in 2006, then it has become the first line treatment for patients with metastatic RCC [5-7].

Sunitinib standard dose is $50 \mathrm{mg}$ once/daily for 4 consecutive weeks followed by 2 weeks off to allow recovery from treatment related adverse events (TRAEs) (4/2 schedule) [8, 9]. Evidence has demonstrated that longterm and high exposure to it lead to severe adverse events (AEs), such as fatigue, hypertension, hand-foot syndrome (HFS), diarrhea and hematological toxicities [10].

In clinical practice, occurrence of AEs resulted in drug interruptions or dose reduction with a unfavorable impact on survival and patients quality of life $[10,11]$. Therefore, many trials were done to find the best schedule that gives the best response with minimal toxicity, increased drug adherence, and enhanced overall time of treatment [3].

Some recent studies evaluated a modified two-week on and one-week off schedule (2/1 schedule) which showed improved clinical outcome and tolerability [12-16]. However, these studies were single-center and retrospective. So, this prospective multi-centric randomized trial was done to evaluate the standard 4/2 schedule vs. a modified schedule (2/1 schedule), then determine which schedule has superior efficacy, tolerability and clinical outcomes.

\section{Material and methods}

This prospective randomized multi-centric study included 70 patients with metastatic RCC who were operated, diagnosed, treated and followed up at; Urology Surgery, Medical Oncology, Clinical Oncology and Nuclear Medicine departments, Faculty of Medicine, Zagazig University, Egypt as well as Clinical Oncology Department, Assiut University, Egypt. The patients collected and followed up in the period from January 2017 to December 2019. 
All patients underwent nephrectomy except five patients diagnosed pathologically by needle biopsy; 3 patients in group 1 and 2 patients in group 2 .

70 patients were randomly assigned into 2 groups:- 40 patients were allocated to group1 and given the standard dosing schedule of sunitinib of $50 \mathrm{mg}$ per day, 4 weeks on and 2 weeks off ( $4 / 2$ schedule) as reported by Motzer et al. [3]. The other 30 patients were admitted to group 2 where they received the alternative dosing schedule of $50 \mathrm{mg}$ per day, 2-week on and 1-week off (2/1 schedule). Treatment was given until disease progression or unacceptable AEs.

In case of severe AEs and/or worsening intolerance, a decision of a dose reduction or stopping of sunitinib was taken by the physician.

All patients underwent initial radiological assessment by computed tomography (CT) chest, abdomen and pelvis Magnetic resonance imaging (MRI) brain and radionuclide bone scan, Positron emission tomography-computed tomography (PET-CT) when indicated, in addition to the laboratory investigations such as complete blood count $(C B C)$, liver function test (LFT), renal function test (RFT), urine analysis, serum calcium. All patients underwent a regular follow up every 6 weeks starting from the end of the 4 weeks of sunitinib (schedule 4/2) and at the end of the second week of sunitinib (schedule $2 / 1$ ). With each clinic visit, the overall and $\geq$ grade 3 incidence of treatment related adverse events (TRAEs) were assessed in each group of our study. A radiological evaluation by CT scan was done to assess the size of tumor every 3 months after starting sunitinib. The radiographic response was assessed according to the Response Evaluation Criteria in Solid Tumors (RECIST) 1.1 [17]. Severe AEs were defined as those with grade $\geq 3$ as classified by the Common Terminology Criteria for Adverse Events (CTCAE), version 4.0 [18]. All patients provided written informed consent. Our work was approved by the Ethical Committee of our institutions.

Patients were considered eligible when they: had histopathologically confirmed metastatic RCC (clear cell carcinoma and non-clear cell carcinoma), were aged $\geq 18$ years, were treatment-naïve metastatic RCC patients, had clinical or radiological metastatic disease with normal organ and bone marrow function. Non-metastatic patients were excluded from the study.

The primary endpoint was to evaluate the treatment related AEs, while the secondary endpoints were evaluation of tumor response, progression-free survival (PFS) and overall survival (OS).

\section{Statistical analysis}

Data was tested for normal distribution using the Shapiro-Walk test. Categorical covariates were compared using the $\chi^{2}$ test or Fisher's exact test. Mann-Whitney $U$ test was used to calculate the difference between quantitative variables in the two groups. The OS and PFS were calculated by the Kaplan-Meier method and Survival curves were compared using the log-rank test. The Cox proportional hazards model was used for univariate analysis. Variables that were statistically significant in the univariate analysis were included in the multivariate Cox proportional hazards model. All tests were two-sided and a $p$-value $\leq 0.05$ was considered statistically significant. All statistical analyses were performed using Statistical Package for Social Sciences (SPSS 24 Inc. Chicago, IL, USA). PFS was defined as the time from the initiation of sunitinib to progression of disease (PD) or death. OS was defined as the time from first administration of sunitinib till death from any cause or missed follow up.

\section{Results}

Table 1 shows the baseline characteristics of patients. Most of them were primarily males (58.6\%). $47.1 \%$ of our patients were $\leq 60$ years and $52.9 \%$ were $>60$ years with median age 60 years (range, 42-68 years). Clear cell carcinoma was the most common pathological subtype (92.9\%) of the patients. $58.6 \%$ of the patients had International Metastatic RCC Database Consortium (IMDC) intermediate-risk features, followed by (31.4\%) had favorable IMDC risk features and 10\% showed poor risk features. The majority of the patients had good performance status (PS) 0-1 about (92.9\%). The most common metastatic sites were the lungs (48.5\%), followed by LNs (20\%), bone (15.7\%), then liver (12.8\%), and brain $2.8 \% .47 .1 \%$ of the patients had tumor size $>10 \mathrm{~cm}$. Positive lymph node (LN) was present in $65.8 \%$ of the patients. The majority of patients had nephrectomy surgery (92.9\%). There were no significant differences between both groups regarding the patients characteristics. The median follow-up time was 23 months with a range of (12-34).

\section{Safety}

Table 2 shows the incidence of AEs of sunitinib according to dosing schedule. All patients $(100 \%)$ had AEs on schedule $4 / 2$ vs. $73.3 \%$ on schedule $2 / 1$ with significant difference between both groups ( $p=0.001$ ). Furthermore, patients who had grade 3 AEs on schedule $2 / 1$ were significantly lower than patients on schedule $4 / 2$ (26.7\% vs. $82.5 \%)$, respectively, with $(p<0.001)$. There were significant differences between both groups regarding the fatigue $(p=0.002)$, thrombocytopenia $(p=0.015)$, diarrhea $(p=0.006)$, hypertension $(p=0.001)$, HFS $(p=0.001)$, mucositis ( $p=0.001)$ and all were in the favor of group 2 (schedule 2/1) in comparison with group 1 (schedule 4/2). Regarding the incidence of grade $3 \mathrm{AEs}$, patients of group 2 (schedule 2/1) showed significantly less AEs than group 1 (schedule 4/2) such as fatigue, diarrhea, hypertension, HFS, mucositis ( $p<0.001)$. The incidence of overall and grade 3 dyspepsia, hypothyroidism, anemia and leucopenia had no significant differences between both groups. Dose reduction was significantly decreased in $2 / 1$ schedule group than $4 / 2$ schedule group ( $13.3 \%$ vs. $95 \%$ ) ( $p=0.001$ ). No one stopped treatment in the $2 / 1$ schedule group vs. 31 patients $(77.5 \%)$ in $4 / 2$ schedule group $(p<0.001)$.

\section{Treatment efficacy and survival outcomes}

As shown in Table 3, we analyzed the tumor response in both groups. The overall response was higher in group 2 (2/1 schedule group) than group 1(4/2 schedule group) 
Table 1. Baseline characteristics of patients treated with sunitinib stratified by sunitinib dose schedules

\begin{tabular}{|c|c|c|c|c|c|c|c|c|}
\hline \multirow[t]{3}{*}{ Variables } & & \multicolumn{4}{|c|}{ Schedules } & \multirow{2}{*}{\multicolumn{2}{|c|}{$\begin{array}{l}\text { Total } \\
n=70\end{array}$}} & \multirow[t]{3}{*}{$p$-value } \\
\hline & & \multicolumn{2}{|c|}{$\begin{array}{c}\text { Group } 1(42) \\
n=40(57.1 \%)\end{array}$} & \multicolumn{2}{|c|}{$\begin{array}{c}\text { Group } 2(2 / 1) \\
n=30(42.8 \%)\end{array}$} & & & \\
\hline & & $n$ & $\%$ & $n$ & $\%$ & $n$ & $\%$ & \\
\hline \multirow[t]{2}{*}{ Age } & $\leq 60$ years & 17 & 42.5 & 16 & 53.3 & 33 & 47.1 & \multirow[t]{3}{*}{0.369} \\
\hline & $>60$ years & 23 & 57.5 & 14 & 46.7 & 37 & 52.9 & \\
\hline \multicolumn{2}{|c|}{ Median age (range, years) } & \multicolumn{2}{|c|}{$61(43-68)$} & \multicolumn{2}{|c|}{$59(42-66)$} & \multicolumn{2}{|c|}{$60(42-68)$} & \\
\hline \multirow[t]{2}{*}{ Sex } & Male & 23 & 57.5 & 18 & 60.0 & 41 & 58.6 & \multirow[t]{2}{*}{0.834} \\
\hline & Female & 17 & 42.5 & 12 & 40.0 & 29 & 41.4 & \\
\hline \multirow{3}{*}{$\begin{array}{l}\text { Pathological } \\
\text { subtype }\end{array}$} & Clear cell ca & 37 & 92.5 & 28 & 93.3 & 65 & 92.9 & \multirow[t]{3}{*}{0.926} \\
\hline & Papillary ca & 2 & 5.0 & 1 & 3.3 & 3 & 4.3 & \\
\hline & Chromophobe ca & 1 & 2.5 & 1 & 3.3 & 2 & 2.9 & \\
\hline \multirow{3}{*}{$\begin{array}{l}\text { IMDC prognostic } \\
\text { score }\end{array}$} & Favorable risk & 11 & 27.5 & 11 & 36.7 & 22 & 31.4 & \multirow[t]{3}{*}{0.427} \\
\hline & Intermediate risk & 26 & 65.0 & 15 & 50.0 & 41 & 58.6 & \\
\hline & Poor risk & 3 & 7.5 & 4 & 13.3 & 7 & 10.0 & \\
\hline \multirow{3}{*}{$\begin{array}{l}\text { ECOG performance } \\
\text { status }\end{array}$} & 0 & 28 & 70.0 & 20 & 66.7 & 48 & 68.6 & \multirow[t]{3}{*}{0.92} \\
\hline & 1 & 9 & 22.5 & 8 & 26.7 & 17 & 24.3 & \\
\hline & $\geq 2$ & 3 & 7.5 & 2 & 6.7 & 5 & 7.1 & \\
\hline \multirow[t]{5}{*}{ Metastatic sites } & Lung & 22 & 55.0 & 12 & 40.0 & 34 & 48.5 & \multirow[t]{5}{*}{0.153} \\
\hline & $\mathrm{LN}$ & 7 & 17.5 & 7 & 23.3 & 14 & 20.0 & \\
\hline & Liver & 2 & 5.0 & 7 & 23.3 & 9 & 12.8 & \\
\hline & Bone & 8 & 20.0 & 3 & 10.0 & 11 & 15.7 & \\
\hline & Brain & 1 & 2.5 & 1 & 3.3 & 2 & 2.8 & \\
\hline \multirow[t]{2}{*}{ Tumor size } & $\leq 10 \mathrm{~cm}$ & 20 & 50.0 & 17 & 56.6 & 37 & 52.8 & \multirow[t]{2}{*}{0.583} \\
\hline & $>10 \mathrm{~cm}$ & 20 & 50.0 & 13 & 43.3 & 33 & 47.1 & \\
\hline \multirow[t]{4}{*}{ T } & 1 & 8 & 20.0 & 7 & 23.3 & 15 & 21.4 & \multirow[t]{4}{*}{0.880} \\
\hline & 2 & 11 & 36.7 & 11 & 36.7 & 22 & 31.4 & \\
\hline & 3 & 12 & 30.0 & 7 & 23.3 & 19 & 27.1 & \\
\hline & 4 & 9 & 22.5 & 5 & 16.7 & 14 & 20.0 & \\
\hline \multirow[t]{2}{*}{ N } & NO & 14 & 35.0 & 10 & 33.3 & 24 & 34.2 & \multirow[t]{2}{*}{0.885} \\
\hline & N1 & 26 & 65.0 & 20 & 66.6 & 46 & 65.8 & \\
\hline \multirow[t]{2}{*}{ Nephrectomy } & No & 3 & 7.5 & 2 & 6.7 & 5 & 7.1 & 0.893 \\
\hline & Yes & 37 & 92.5 & 28 & 93.3 & 65 & 92.9 & \\
\hline
\end{tabular}

(63.3\% vs. $47.5 \%)$ with no statistical differences between both groups. Complete response (CR) was achieved in one patient $(2.5 \%)$ of group 1 (4/2 schedule group) vs. 3 patients $(10 \%)$ of group 2 (2/1 schedule group). A total of 34 $(48.6 \%)$ patients had partial response (PR); 18 were in the group 1 (4/2 schedule), 16 were in group 2 (2/1 schedule). Seventeen (24.3\%) patients had stable disease (SD); $11 \mathrm{pa-}$ tients (27.5\%) were in group 1 (4/2 schedule) and 6 (20\%) patients were in group 2 ( $2 / 1$ schedule). Fifteen patients showed PD;10 were in group 1 (4/2 schedule), while 5 were in group 2 (2/1 schedule) with no statistical differences were observed between both groups. At time of the last follow-up, progression occurred in 32 (45.7\%) patients; 21 (52.5\%) patients were in group 1 (4/2 schedule), 11 (36.7\%) were in group 2 (2/1 schedule) without any statistical differences between both groups. Death occurred in 45 (64.3\%) patients; 26 (65\%) patients in group 1 (4/2 schedule), 19 (63.3\%) in group 2 (2/1 schedule) with no statistical differences between both groups.
We sub-analyzed and compared PFS and OS among patients with the two dosing schedules as in Table 4 and Figures $1-3$. OS rate was insignificantly higher in group 2 (2/1 schedule) (18.8\%) vs. (4.5\%) in group 1 (4/2 schedule) $(p<0.639)$, with the median OS $24 \pm 0.6$ months for group 1 and $25 \pm 0.7$ months for group 2 . Regarding PFS rate was significantly higher in group 2 (2/1 schedule) (60.9\%) vs. (38.6\%) in group 1 ( $4 / 2$ schedule) $(p=0.008)$, with median PFS $16 \pm 0.4$ months for group 1 but it was not reached in group 2 .

We analyzed potential risk factors for PFS in patients with metastatic RCC treated with sunitinib (Table 5). By using Cox's regression model, univariate analysis indicated that IMDC prognostic classification (poor risk category) $(p<0.037)$, ECOG performance status ( $\geq 2$ vs. 0 ) $(p<0.001)$, tumor size $>10 \mathrm{~cm}(p<0.004)$ and treatment schedule (group 1) $(p<0.018)$ were statistically associated with poor PFS.

Further multivariate analysis suggested that age $>60$ years (hazard ratio [HR]) is 6.4, confidence interval $(\mathrm{Cl})$ 
Table 2. Incidence of major adverse events according to the sunitinib dose schedules

\begin{tabular}{|c|c|c|c|c|c|c|c|c|c|c|c|}
\hline \multirow[t]{3}{*}{ Schedules } & & \multicolumn{4}{|c|}{$\begin{array}{c}\text { Group } 1(4 / 2) \\
n=40\end{array}$} & \multicolumn{4}{|c|}{$\begin{array}{c}\text { Group } 2(2 / 1) \\
n=30\end{array}$} & \multicolumn{2}{|c|}{$p$-value } \\
\hline & & \multicolumn{2}{|c|}{ Overall } & \multicolumn{2}{|c|}{$\geq \mathrm{G} 3$} & \multicolumn{2}{|c|}{ Overall } & \multicolumn{2}{|c|}{$\geq \mathrm{G} 3$} & \multirow[t]{2}{*}{ Overall } & \multirow[t]{2}{*}{$\geq \mathrm{G} 3$} \\
\hline & & $n$ & $\%$ & $n$ & $\%$ & $n$ & $\%$ & $n$ & $\%$ & & \\
\hline \multirow[t]{2}{*}{ Overall toxicity } & Absent & 0 & 0 & 7 & 17.5 & 8 & 26.7 & 22 & 73.3 & \multirow[t]{2}{*}{0.001} & \multirow[t]{2}{*}{$<0.001$} \\
\hline & Present & 40 & 100.0 & 33 & 82.5 & 22 & 73.3 & 8 & 26.7 & & \\
\hline \multirow[t]{2}{*}{ Fatigue } & Absent & 16 & 40.0 & 31 & 77.5 & 28 & 93.3 & 28 & 93.3 & \multirow[t]{2}{*}{0.002} & \multirow[t]{2}{*}{$<0.001$} \\
\hline & Present & 24 & 60.0 & 9 & 22.5 & 2 & 6.7 & 2 & 6.7 & & \\
\hline \multirow[t]{2}{*}{ Thrombocytopenia } & Absent & 24 & 60.0 & 31 & 77.5 & 26 & 86.7 & 29 & 96.7 & \multirow[t]{2}{*}{0.015} & \multirow[t]{2}{*}{0.077} \\
\hline & Present & 16 & 40.0 & 9 & 22.5 & 4 & 13.3 & 1 & 3.3 & & \\
\hline \multirow[t]{2}{*}{ Diarrhea } & Absent & 19 & 47.5 & 36 & 90.0 & 24 & 80.0 & 28 & 93.3 & \multirow[t]{2}{*}{0.006} & \multirow[t]{2}{*}{$<0.001$} \\
\hline & Present & 21 & 52.5 & 4 & 10.0 & 6 & 20.0 & 2 & 6.7 & & \\
\hline \multirow[t]{2}{*}{ Hypertesion } & Absent & 19 & 47.5 & 35 & 87.5 & 29 & 96.7 & 29 & 96.7 & \multirow[t]{2}{*}{0.001} & \multirow[t]{2}{*}{$<0.001$} \\
\hline & Present & 21 & 52.5 & 5 & 12.5 & 1 & 3.3 & 1 & 3.3 & & \\
\hline \multirow{2}{*}{$\begin{array}{l}\text { Hand-foot } \\
\text { syndrome }\end{array}$} & Absent & 16 & 40.0 & 33 & 82.5 & 26 & 86.7 & 27 & 90.0 & \multirow[t]{2}{*}{0.001} & \multirow[t]{2}{*}{$<0.001$} \\
\hline & Present & 24 & 60.0 & 7 & 17.5 & 4 & 13.3 & 3 & 10.0 & & \\
\hline \multirow[t]{2}{*}{ Mucositis } & Absent & 16 & 40.0 & 36 & 90.0 & 27 & 90.0 & 28 & 93.3 & \multirow[t]{2}{*}{0.001} & \multirow[t]{2}{*}{$<0.001$} \\
\hline & Present & 24 & 60.0 & 4 & 10.0 & 3 & 10.0 & 2 & 6.7 & & \\
\hline Dyspepsia & Absent & 34 & 85.0 & 38 & 95.0 & 26 & 86.7 & 30 & 100.0 & 0.844 & 0.214 \\
\hline & Present & 6 & 15.0 & 2 & 5.0 & 4 & 13.3 & 0 & 0.0 & & \\
\hline Hypothyroidism & Absent & 28 & 70.0 & 39 & 97.5 & 23 & 76.7 & 30 & 100.0 & 0.535 & 0.383 \\
\hline & Present & 12 & 30.0 & 1 & 2.5 & 7 & 23.3 & 0 & 0.0 & & \\
\hline Anaemia & Absent & 26 & 65.0 & 36 & 90.0 & 22 & 73.3 & 28 & 93.3 & 0.457 & 0.622 \\
\hline & Present & 14 & 35.0 & 4 & 10.0 & 8 & 26.7 & 2 & 6.7 & & \\
\hline Leukopenia & Absent & 23 & 57.5 & 34 & 85.0 & 21 & 70.0 & 28 & 93.3 & 0.284 & 0.278 \\
\hline & Present & 17 & 42.5 & 6 & 15.0 & 9 & 30.0 & 2 & 6.7 & & \\
\hline
\end{tabular}

[2.2-18.5], $p=0.001$ ), IMDC prognostic classification (poor risk category) (HR 0.2 and $\mathrm{Cl}[0.0-0.6],(p=0.005)$, treatment schedule (group 1) (HR 0.2 and Cl [0.1-0.6], ( $p=0.003)$, were independent poor prognostic factors of PFS.

\section{Discussion}

Sunitinib is the principal treatment of patients with metastatic RCC as it was documented in many trials [3, $19,20]$. But it has many common adverse effects such as, diarrhea, fatigue, HFS, hypertension and thrombocytope- nia, which are increasing throughout the cycle, and worsen most in the last two weeks of schedule 4/2; hence, it compromises the treatment continuation which result in interference with its therapeutic activity [3, 21,22].

This raises the need to modify the strategy of administration of this drug to avoid drug discontinuation which could improve the outcome, decrease patients as well as their caregivers suffering, improve QOL of the patients; in addition, reduce the burden of health care providers [23, 24]. Therefore, we performed this study to compare both schedules of sunitinib administration in relation to the

Table 3. Outcome of patients as regard to the sunitinib dose schedules

\begin{tabular}{|c|c|c|c|c|c|c|c|c|}
\hline \multirow[t]{3}{*}{ Variables } & & \multicolumn{4}{|c|}{ Schedules } & \multirow{2}{*}{\multicolumn{2}{|c|}{$\begin{array}{c}\text { Total } \\
n=70\end{array}$}} & \multirow[t]{3}{*}{$p$-value } \\
\hline & & \multicolumn{2}{|c|}{$\begin{array}{c}\text { Group } 1(42) \\
n=40(57.1 \%)\end{array}$} & \multicolumn{2}{|c|}{$\begin{array}{c}\text { Group } 2(2 / 1) \\
n=30(42.8 \%)\end{array}$} & & & \\
\hline & & $n$ & $\%$ & $n$ & $\%$ & $n$ & $\%$ & \\
\hline \multirow[t]{5}{*}{ Response } & OAR & 19 & 47.5 & 19 & 63.3 & 38 & 54.2 & \multirow[t]{5}{*}{0.41} \\
\hline & $C R$ & 1 & 2.5 & 3 & 10.0 & 4 & 5.7 & \\
\hline & $P R$ & 18 & 45.0 & 16 & 53.3 & 34 & 48.6 & \\
\hline & SD & 11 & 27.5 & 6 & 20.0 & 17 & 24.3 & \\
\hline & PD & 10 & 25.0 & 5 & 16.7 & 15 & 21.4 & \\
\hline \multirow[t]{2}{*}{ Progression } & Absent & 19 & 47.5 & 19 & 63.3 & 38 & 54.3 & \multirow[t]{2}{*}{0.188} \\
\hline & Present & 21 & 52.5 & 11 & 36.7 & 32 & 45.7 & \\
\hline \multirow[t]{2}{*}{ Death } & Absent & 14 & 35.0 & 11 & 36.7 & 25 & 35.7 & \multirow[t]{2}{*}{0.885} \\
\hline & Present & 26 & 65.0 & 19 & 63.3 & 45 & 64.3 & \\
\hline
\end{tabular}


Table 4. The overall and progression-free survival rate in relation to the sunitinib dose schedules

\begin{tabular}{|c|c|c|c|c|c|c|c|c|c|c|}
\hline \multirow[t]{2}{*}{ Schedules } & \multirow[t]{2}{*}{ Total $n$} & \multirow{2}{*}{$\begin{array}{c}n \text { of } \\
\text { events }\end{array}$} & \multicolumn{2}{|c|}{ Censored } & \multirow{2}{*}{$\begin{array}{c}\text { Survival } \\
\text { rate } \%\end{array}$} & \multirow[t]{2}{*}{$p$-value } & \multicolumn{4}{|c|}{ Survival time (months) } \\
\hline & & & $n$ & $\%$ & & & Mean \pm SE & $95 \% \mathrm{Cl}$ & $\mathrm{Me} \pm \mathrm{SE}$ & $95 \% \mathrm{Cl}$ \\
\hline \multicolumn{11}{|l|}{ Overall survival } \\
\hline Group 1 (4/ 2) & 40 & 26 & 14 & 35.0 & 4.50 & \multirow[t]{3}{*}{0.639} & $24.1 \pm 0.6$ & $21.9-25.2$ & $24 \pm 0.6$ & $23.8-26.2$ \\
\hline Group $2(2 / 1)$ & 30 & 19 & 11 & 36.7 & 18.80 & & $25 \pm 1.2$ & $22.8-27.3$ & $25 \pm 0.7$ & $23.7-26.4$ \\
\hline Overall & 70 & 45 & 25 & 35.7 & 10.40 & & $24.5 \pm 0.6$ & $23.3-25.7$ & $25 \pm 0.5$ & $24.1-25.9$ \\
\hline \multicolumn{11}{|c|}{ Progression-free survival } \\
\hline Group $1(4 / 2)$ & 40 & 21 & 19 & 47.5 & 38.60 & \multirow[t]{3}{*}{0.008} & $19.6 \pm 1$ & $17.6-21.6$ & $16 \pm 0.4$ & $15.3-16.7$ \\
\hline Group $2(2 / 1)$ & 30 & 11 & 19 & 63.3 & 60.90 & & $27.3 \pm 1.6$ & $24.2-30.4$ & NR & \\
\hline Overall & 70 & 32 & 38 & 54.3 & 47.70 & & $24.4 \pm 1.2$ & $22.1-26.7$ & 18 & \\
\hline
\end{tabular}

NR - not reached
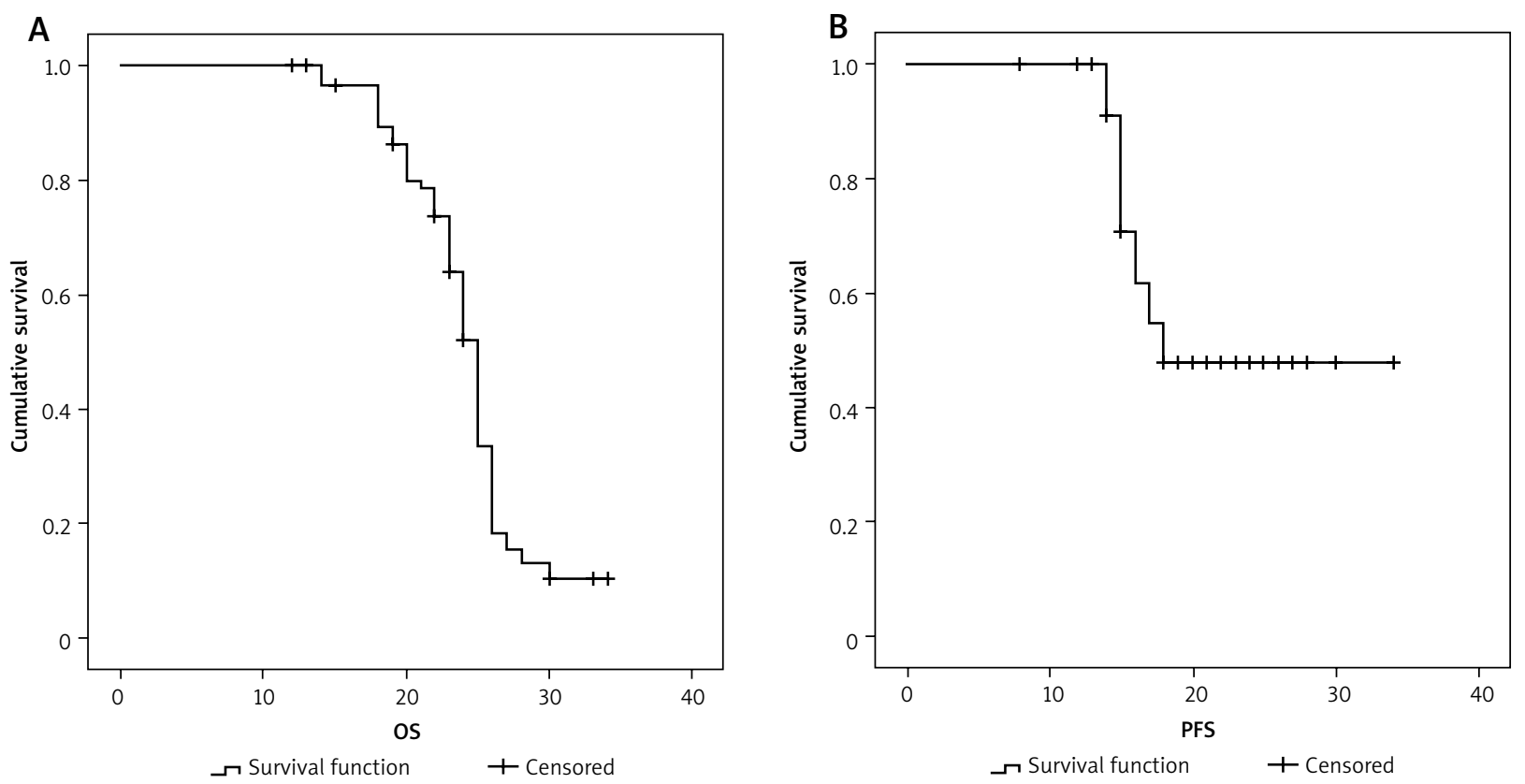

Fig. 1. Kaplan-Meier curves illustrating the overall survival (OS) and progression-free survival (PFS) (months) in all patients

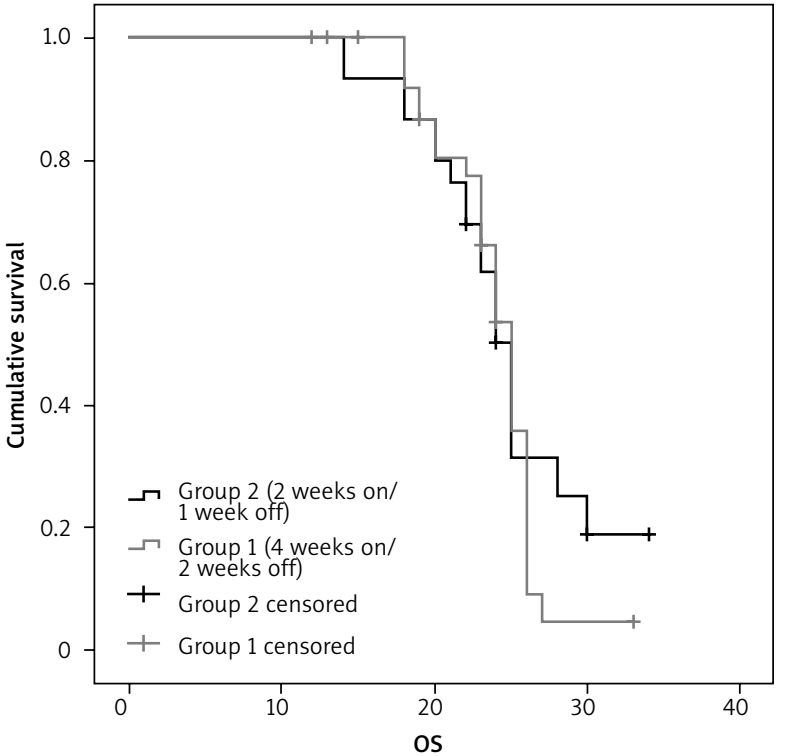

Fig. 2. Kaplan-Meier survival curves illustrating the overall survival rate differences (months) in group 1 vs. group 2

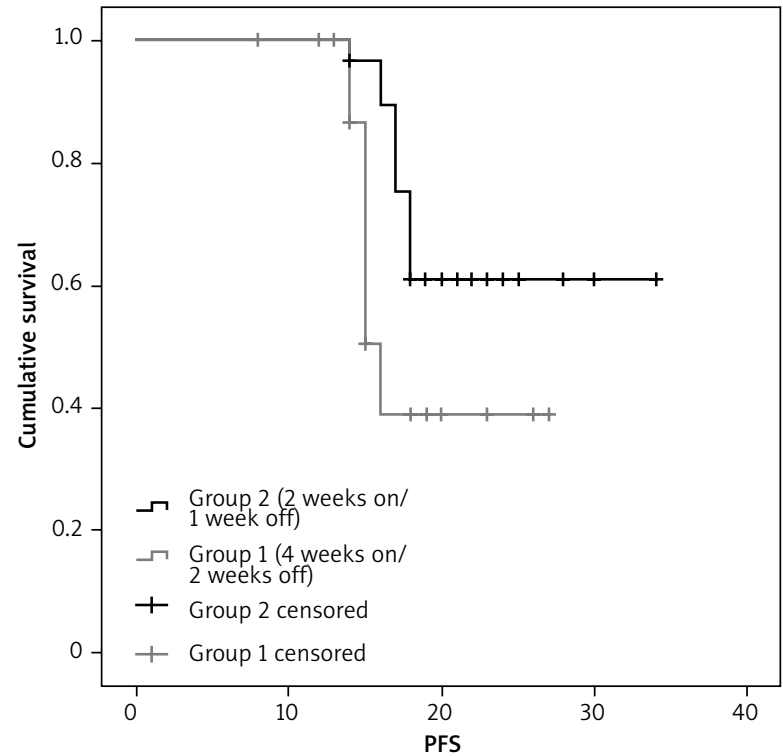

Fig. 3. Kaplan-Meier survival curves illustrating the progression-free survival rate differences (months) in group 1 vs. group 2 
Table 3. Outcome of patients as regard to the sunitinib dose schedules

\begin{tabular}{|c|c|c|c|c|c|c|c|c|}
\hline \multirow[t]{3}{*}{ Covariates } & \multicolumn{4}{|c|}{ Univariate } & \multicolumn{4}{|c|}{ Multivariate } \\
\hline & \multirow[t]{2}{*}{$\mathrm{HR}$} & \multicolumn{2}{|c|}{$95.0 \% \mathrm{Cl}$ for $\mathrm{HR}$} & \multirow[t]{2}{*}{ Sig. } & \multirow[t]{2}{*}{$\mathrm{HR}$} & \multicolumn{2}{|c|}{$95.0 \% \mathrm{Cl}$ for $\mathrm{HR}$} & \multirow[t]{2}{*}{ Sig. } \\
\hline & & Lower & Upper & & & Lower & Upper & \\
\hline Age $(>60$ years vs. $\leq 60)$ & 0.95 & 0.90 & 1.01 & 0.076 & 6.4 & 2.2 & 18.5 & 0.001 \\
\hline Sex (male vs. female) & 1.80 & 0.89 & 3.62 & 0.12 & & & & \\
\hline \multicolumn{9}{|l|}{ Pathological subtype } \\
\hline Papillary ca vs. clear cell ca & 1.47 & 0.35 & 6.20 & 0.597 & & & & \\
\hline Chromophobe ca vs. clear cell ca & 2.12 & 0.51 & 8.91 & 0.304 & & & & \\
\hline $\begin{array}{l}\text { IMDC prognostic classification } \\
\text { (poor vs. favorable } \& \text { intermediate) }\end{array}$ & 1.57 & 1.03 & 2.38 & 0.037 & 0.2 & 0.0 & 0.6 & 0.005 \\
\hline \multicolumn{9}{|l|}{ ECOG performance status } \\
\hline 1 vs. 0 & 3.79 & 1.81 & 7.95 & $<0.001$ & 2.2 & 1.0 & 4.8 & 0.055 \\
\hline$\geq 2$ vs. 0 & 3.27 & 0.93 & 11.51 & 0.065 & 2.7 & 0.7 & 11.1 & 0.168 \\
\hline Tumor size $>10 \mathrm{~cm}$ vs. $\leq 10 \mathrm{~cm}$ & 8.21 & 1.96 & 34.36 & 0.004 & 0.2 & 0.1 & 1.1 & 0.063 \\
\hline N (1 vs. 0) & 0.82 & 0.17 & 3.96 & 0.806 & & & & \\
\hline Nephrectomy (no vs. yes) & 22.28 & 0.04 & 171.1 & 0.328 & & & & \\
\hline Schedules (group 1 vs. 2) & 2.47 & 1.17 & 5.23 & 0.018 & 0.2 & 0.1 & 0.6 & 0.003 \\
\hline
\end{tabular}

Multivariate Cox regression analysis model was done using any predictor with $p<0.1$ in univariate analysis

toxicity, efficacy and outcome. Reduction of the dose or stopping sunitinib was done for patients who received 4/2 schedule if they had severe AEs and/or worsening intolerance without doing shifting as it is not the aim of our study.

In our study, we found that the overall AEs were present in all patients (100\%) on schedule $4 / 2$ vs. $73.3 \%$ on schedule $2 / 1$ with significant difference between both groups $(p=0.001)$ such as fatigue $(p=0.002)$, thrombocytopenia $(p=0.015)$, diarrhea $(p=0.006)$, hypertension $(p=0.001)$, HFS ( $p=0.001)$ and mucositis $(p=0.001)$. All were in favor of group 2 (schedule $2 / 1$ ) in comparison to group 1 (schedule 4/2). And the grade 3 AEs were statistically significant less experienced in patients on schedule $2 / 1$ than the patients on schedule $4 / 2$ ( $26.7 \%$ vs. $82.5 \%)$, respectively ( $p<0.001)$ such as; fatigue, hypertension, HFS, mucositis, diarrhea ( $p<0.001$ ). The alternative $2 / 1$ dose schedule had a significant decline of drug toxicity induced by dose reduction than $4 / 2$ schedule group (13.3\% vs. 95\%) ( $p=0.001)$ with no treatment interruption. It was noticed that the patients with poor ECOG PS has more worse toxicity and decreased tolerability in group 1 than group 2 .

Our findings were consistent with Eldin [25] study which demonstrated that the alternative $2 / 1$ schedule of sunitinib showed better toxicity profile compared to the traditional $4 / 2$ schedule, with statistical significance for fatigue $(p=0.018)$, HFS $(p=0.008)$, mucositis $(p=0.010)$, hypertension $(p=0.038)$, diarrhea $(p=0.03)$, and thrombocytopenia ( $p=0.023)$, because of dose reduction which was implemented due to drug toxicity. Neri et al. [15] conducted a phase II trial which showed improvement of the toxicity in $2 / 1$ schedule group with a dose reduction occurred in only $9 \%$ patients which was in line with our study.

Our results were also in line with Karon study [26] who performed a single-arm, multicenter, phase 2 trial on 59 patients with metastatic RCC who received $2 / 1$ schedule of sunitinib. They concluded that nearly one fourth of the patients had grade 3 fatigue, diarrhea or hand-foot syndrome, only $37 \%$ required dose reductions while $90 \%$ of patients continued treatment without stopping and avoided protracted high-grade toxicities.

But some studies examined the shifting from $4 / 2$ schedule to $2 / 1$ schedule $(4 / 2-2 / 1)$, others compared it with the other two schedules (4/2 and 2/1 schedules) and checked if there were significant and intolerable adverse effects or not, e.g. Miyake et al. [27], Bracarda et al. [28] and Najjar et al. [14] who stated that switching from schedule 4/2 to schedule 2/1 lead to decrease the incidence and severity of sunitinib-induced toxicity. In addition, a significant reduction in toxicities (grade 3-4) was found in some trials such as fatigue, hypertension, hand-foot syndrome and thrombocytopenia $[14,28,29]$. These studies confirmed the results of other monocentric experiences [14-18]. Moreover, marked improvement of QOL was noticed [27].

Regarding the efficacy in our study, the overall response (OAR) was found to be insignificantly higher in $2 / 1$ schedule than $4 / 2$ schedule. This insignificance might be due to the small number of patients.

Eldin [25] and Zhang X et al. [28] found that the overall response (OAR) was not better in group 2 ( $2 / 1$ schedule) which was consistent with our findings. They stated that this result was due to the small sample size.

In addition, Jonasch et al. study [23] showed that sunitinib (2/1 strategy) resulted in high efficacy, low rate of treatment discontinuation and maintained patients, QOL. Also, our findings were supported by Bracarda et al. [28] who stated that giving a 4/2-2/1 schedule did not impair efficacy. Furthermore, Karon [26] demonstrated that sunitinib showed high efficacy of $2 / 1$ schedule with overall response rate 57\%, with median PFS 13.7 months. However, they stated that the majority of the patients had intermediate risk (67\%),while $10 \%$ of the patients had poor risk. Therefore, their non-randomized data supported the use of alternate 2/1 schedule to maintain QOL and increase duration of treatment. 
In our trial, at the time of the last follow-up, progression was less in group 2 (2/1 schedule) than in group 1 (4/2 schedule) without any statistical differences between both groups. Death was not significantly higher in group 1 (4/2 schedule) than group 2 (2/1 schedule).

Regarding OS rate was insignificantly higher in group 2 ( $2 / 1$ schedule) than in group 1 ( $4 / 2$ schedule) $(p=0.639)$ with the median OS of $24 \pm 0.6$ months for group 1 and $25 \pm 0.7$ months for group 2 . Regarding PFS rate was significantly higher in group 2 (2/1 schedule) than group 1 (4/2 schedule) ( $p=0.008)$, with median PFS $16 \pm 0.4$ months for group 1 but it wasn't reached in group 2 . The following criteria were considered independent poor prognostic factors of PFS by multivariate analysis;

age $>60$ years $(p=0.001)$, IMDC prognostic classification (poor risk category) $(p=0.005)$, treatment schedule (group 1) ( $p=0.003)$.

Our findings were in line with Eldin study [25] who found no difference in survival between both groups. However, the median PFS was 15 months and 17 months in groups 1 and 2 , respectively and the median OS was 24 months and 23 months for groups 1 and 2, respectively.

Zhang $X$ et al. [29] study demonstrated that the median PFS was longer in 4/2-2/1 schedule when compared with both the $2 / 1$ and $4 / 2$ groups (25.0, 11.0,12.5 months, respectively; $p=0.003)$. Similarly, OS was longer in $p a-$ tients in the 4/2-2/1 group than patients in the other two groups (median OS: 53.0, 28.0, 21 months, respectively; $p$ $=0.03)$. However, the prognostic score $($ IMDC) $\geq 3$ and a 4/2-2/1 schedule were considered as independent prognostic factors of PFS by multivariate analysis. In addition, nephrectomy was independent favorable prognostic factor ( $p=0.002$ ), while IMDC $\geq 3$ was significantly associated with an increased mortality risk $(p=0.022)$. Furthermore, he stated that this treatment schedule may improve the clinical practice by giving personalized patient management and achieving individualized therapy using this schedule to patients with unfavorable IMDC risk category and higher tumor burden due to the survival improvement with 4/2-2/1 schedule. But this study had some limitations such as; it was a retrospective study with unavoidable biases of decision making and patient selection, limited medical records or reporting bias from physicians and patients resulting in bias of AEs evaluation, in addition inability to assess the patient compliance during treatment.

Furthermore, Bracarda et al. [28] stated, that there was no inferiority of the efficacy of 4/2-2/1 schedule regarding the survival as it showed longer PFS. They explained that by increasing drug exposure which was associated with in creased efficacy and survival, as well as improved patients, clinical characteristics in the 4/2-2/1 schedule group than other patients groups. But it has some limitations such as its retrospective design, the use of a monocentric external control group, and the observational nature of the analysis. Also the small group of patients which started sunitinib on a 2/1 schedule, caused the small sample size and the negative selection bias of this group [28].

In addition, Britten et al. showed a survival benefits of $2 / 1$ schedule and compared them with the worse outcome of the 4/2 schedule, which was in line with our results.
They explained this result by the prolonged drug exposure [30].

\section{Study limitations}

Small sample size and doing our work on Egyptian patients only are considered limitations of our study, so further prospective studies with a larger number of patients with different ethnicities are needed to reach the final conclusion regarding the better dose schedule of sunitinib in metastatic RCC.

\section{Conclusions}

Our study supported giving sunitinib in patients with metastatic RCC using 2:1 schedule as it was associated with less toxicity profile, better efficacy with improved PFS comparing to $4 / 2$ schedule.

\section{The authors declare no conflict of interest.}

\section{References}

1. Janzen NK, Kim HL, Figlin RA, Belldegrun AS. Surveillance after radical or partial nephrectomy for localized renal cell carcinoma and management of recurrent disease. Urol Clin North Am 2003; 30: 843-852.

2. Motzer RJ, Rini BI, Bukowski RM, et al. Sunitinib in patients with metastatic renal cell carcinoma. JAMA 2006; 295: 2516-2524.

3. Motzer RJ, Hutson TE, Tomczak P, et al. Sunitinib versus interferon alpha in metastatic renal-cell carcinoma. N Engl J Med 2007; 356: 115-124.

4. Motzer RJ, Hutson TE, Tomczak P, et al. Overall survival and updated results for sunitinib compared with interferon alpha in patients with metastatic renal cell carcinoma. J Clin Oncol 2009; 27: 35843590 .

5. Choueiri TK. Clinical treatment decisions for advanced renal cell cancer. J Natl Compr Canc Netw 2013; 11 (5 Suppl): 694-697.

6. Escudier B, Albiges L, Sonpavde G, et al. Optimal management of metastatic renal cell carcinoma: current status. Drugs 2013; 73 : 427-438.

7. Kalra B, Rini I, Jonasch E. Alternate sunitinib schedules in patients with metastatic renal cell carcinoma. Ann Oncol 2015; 26: 13001304.

8. SUTENT ${ }^{\circledR}$ Summary of Product Characteristics. Pfizer 2014

9. Faivre S, Delbaldo C, Vera K, et al. Safety, pharmacokinetic, and antitumor activity of SU11248, a novel oral multitarget tyrosine kinase inhibitor, in patients with cancer. J Clin Oncol 2006; 24: 25-35.

10. Houk BE, Bello CL, Poland B, et al. Relationship between exposure to sunitinib and efficacy and tolerability endpoints in patients with cancer: results of a pharmacokinetic/pharmacodynamic meta-analysis. Cancer Chemother Pharmacol 2010; 66: 357-371.

11. Ravaud A. How to optimise treatment compliance in metastatic renal cell carcinoma with targeted agent s. Ann Oncol 2009; 20 (Suppl 1): i7-12.

12. Kondo T, Takagi T, Kobayashi H, et al. Superior tolerability of altered dosing schedule of sunitinib with 2-weeks-on and 1-weekoff in patients with metastatic renal cell carcinoma - comparison to standard dosing schedule of 4-weeks-on and 2-weeks-off. Jpn J Clin Oncol 2014; 44: 270-277.

13. Atkinson BJ, Kalra S, Wang X, et al. Clinical outcomes in metastatic renal cell carcinoma patients treated with alternative sunitinib schedules. J Urol 2014; 191: 611-618.

14. Najjar YG, Mittal K, Elson P, et al. A 2 weeks on and 1 week off schedule of sunitinib is associated with decreased toxicity in metastatic renal cell carcinoma. Eur J Cancer 2014; 50: 1084-1099.

15. Neri B, Vannini A, Brugia M, et al. Biweekly sunitinib regimen reduces toxicity and retains efficacy in metastatic renal cell carcino- 
ma: a single-center experience with 31 patients. Int J Urol 2013; 20: 478-483.

16. Bjarnason GA, Khalil B, Hudson JM, et al. Outcomes in patients with metastatic renal cell cancer treated with individualized sunitinib therapy: correlation with dynamic microbubble ultrasound data and review of the literature. Urol Oncol 2014; 32: 480-487.

17. Eisenhauer EA, Therasse P, Bogaerts J, et al. New response evaluation criteria in solid tumours: revised RECIST guideline (ver sion 1.1). Eur J Cancer 2009; 45: 228-247.

18. National Cancer Institute (U.S). Common Terminology Criteria for Adverse Events v 4.0. Bethesda, Md: U.S Dept of Health and Human Services, National Institutes of Health, National Cancer Institute 2009

19. Gore ME, Szczylik C, Porta C, et al. Safety and efficacy of sunitinib for metastatic renal-cell carcinoma: an expanded-access trial. Lancet Oncol 2009;10: 757-763.

20. Miyake H, Miyazaki A, Harada K, Fujisawa M. Assessment of efficacy, safety and quality of life of 110 patients treated with sunitinib as first-line therapy for metastatic renal cell carcinoma: experience in real-world clinical practice in Japan. Med Oncol 2014; 31: 978.

21. Motzer RJ, Hutson TE, Cella D, et al. Pazopanib versus sunitinib in metastatic renal-cell carcinoma. N Engl J Med 2013; 369: 722-731.

22. Sternberg CN, Davis ID, Mardiak J, et al. Pazopanib in locally advanced or metastatic renal cell carcinoma: Results of a random ized phase III trial. J Clin Oncol 2010; 28: 1061-1068.

23. Jonasch E, Slack R, Geynisman D, et al. Phase II Study of Two Weeks on, One Week off Sunitinib Scheduling in Patients With Metastatic Renal Cell Carcinoma. J Clin Oncol 2018; 36: 1588-1593.

24. Houk BE, Bello CL, Poland B, Rosen LS, Demetri GD, Motzer RJ. Relationship between exposure to sunitinib and efficacy and tolerability endpoints in patients with cancer: results of a pharmacokinetic/pharmacodynamic meta-analysis. Cancer Chemother Pharmacol 2010; 66: 357-371.

25. Eldin M. Sunitinib 4/2 Versus 2/1 Schedule for Patients With Metastatic Renal Cell Carcinoma: Tertiary Care Hospital Experience. Clin Genitourinary Cancer 2017; 15: e455-62.

26. Karon A. Alternate 2:1 sunitinib schedule showed safety gains in renal cell carcinoma. 2018; https://doi.org/10.1200/ JCO.2017.77.1485.

27. Miyake H, Harada K, Miyazaki A, Fujisawa M. Improved health-related quality of life of patients with metastatic renal cell carcino ma treated with a 2 weeks on and 1 week off schedule of sunitinib. Med Oncol 2015; 32: 78.

28. Bracarda S, lacovelli R, Boni L, et al. Sunitinib administered on 2/1 schedule in patients with metastatic renal cell carcinoma: the RAINBOW analysis. Ann Oncol 2015; 26: 2107-2113.

29. Zhang X, Sun G, Zhao J, et al. Improved long-term clinical outcomes and safety profile of sunitinib dosing schedule with $4 / 2$ switched to $2 / 1$ in patients with metastatic renal cell carcinoma. J Cancer 2018; 9: 3303-3310.

30. Britten CD, Kabbinavar F, Hecht JR, et al. A phase I and pharmacokinetic study of sunitinib administered daily for 2 weeks, followed by a 1-week off period. Cancer Chemother Pharmacol 2008; 61 515-524.

\section{Address for correspondence}

Lobna A. Abdelaziz

Clinical Oncology and Nuclear Medicine Department Faculty of Medicine Zagazig University

Zagazig, Egypt

e-mail: mmlobna90@gmail.com

Submitted: 29.08 .2020

Accepted: 2.11 .2020 